\title{
The Story of Cystic Fibrosis 1965-2015
}

\author{
John Massie, ${ }^{1,2,3}$ Phillip Robinson, ${ }^{1,2,3}$ Peter Cooper ${ }^{4}$
}

1. Department of Respiratory and Sleep Medicine, Royal Children's Hospital, Melbourne

2. Department of Paediatrics, University of Melbourne

3. Infection, Immunity and Environment Theme, Murdoch Children's Research

Institute

4. Department of Respiratory and Sleep Medicine, Children's Hospital at Westmead, Sydney

$\infty$

Correspondence

A/Prof John Massie

Department of Respiratory Medicine

Royal Children's Hospital

50 Flemington Road.

Parkville. VIC 3052. Australia

Ph: 61393455818

Fax: 61393459154

john.massie@rch.org.au

Key Words: cystic fibrosis

Word Count: 2402

This is the author manuscript accepted for publication and has undergone full peer review but has not been through the copyediting, typesetting, pagination and proofreading process, which may lead to differences between this version and the Version of Record. Please cite this article as doi: 10.1111/jpc.13309

This article is protected by copyright. All rights reserved. 


\section{Abstract}

There have been dramatic changes in the care of children with cystic fibrosis (CF) from 1965 to 2015. The initial improvements were due to incremental gains in medical knowledge and better use of available therapies. Some CF specific drugs were developed (rhDNase and purified tobramycin for inhalation) but these simply delayed the progression of the lung damage. The discovery of the cystic fibrosis transmembrane conductance regulator (CFTR) gene in 1989 created an explosion of knowledge of airway biology and CF pathophysiology. Now mutation specific therapy to potentiate mutated CFTR is available for some patients with CF and is transforming their lives. Further advances are eagerly anticipated to benefit all patients with $\mathrm{CF}$.

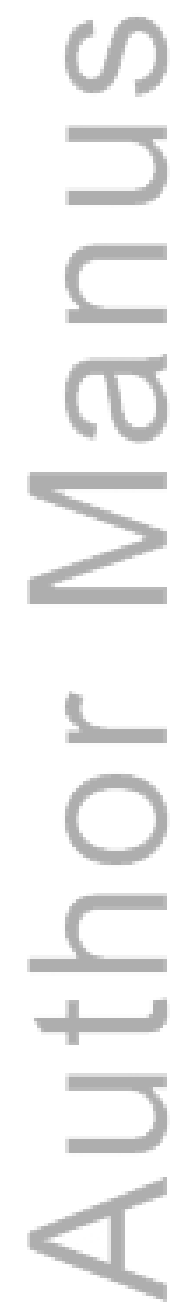

This article is protected by copyright. All rights reserved. 


\section{The pre-history of cystic fibrosis}

This is the story of 50 years of cystic fibrosis from 1965, to coincide with the first 50 years of the Journal of Paediatric and Child Health. ${ }^{1}$ Interestingly, 50 years is now the expected lifespan of a child born with cystic fibrosis (CF) today. In today's terms this is still far too short, but when the Journal was first published, CF usually caused death before the age of 5 years. However, the story of CF starts much earlier, with threads of the story known for centuries. "Beware the child who tastes salty for he is bewitched and will soon die" is a German medieval saying. In 1938 Dorothy Anderson distinguished CF from coeliac disease and coined the term "fibrocystic disease of the pancreas", emphasising that CF classically presented with failure to thrive. The next clinical observation was serendipitous: Paul di'Sant Agnese realised that patients presenting to hospital with dehydration during a 1947 New York heatwave had fibrocystic disease. This eventually led to the sweat test (1959) that was the first definitive test for $\mathrm{CF}$. There was now a recognised clinical disease and a test to confirm it.

In this paper we will describe the treatment of patients with cystic fibrosis born in 1965, 1995 and 2015. We will also describe the transformation of knowledge about CF in the years 1965-1995 (the Clinical Era) and 1995-2015 (the Genetic Era)

\section{Cystic fibrosis in a child born in $\mathbf{1 9 6 5}$}

Kylie was 3 years old in 1968. She weighed $22 \mathrm{lb}(10 \mathrm{~kg})$ and stood 34 inches $(85 \mathrm{~cm})$ high. Her parents had been taking her to doctors since she was six weeks old, worried about her poor weight gain and foul smelling stools. She often coughed and had significant digital clubbing and a distended abdomen. She had three admissions to hospital for pneumonia. In desperation, the family took her to the Children's Hospital and the paediatrician arranged a sweat test using a pad and gauze method. Her sweat sodium was $98 \mathrm{mmol} / \mathrm{L}$ and sweat chloride 105mmol/L (CF range $>60 \mathrm{mmol} / \mathrm{L}$ ). 
Cystic fibrosis was diagnosed and the parents heard the difficult news that there was little that could be done. Kylie remained under the care of the paediatrician at the Children's Hospital. A low fat diet was recommended to normalise the stool pattern. A new antibiotic, minocycline, was started with some improvement in her cough, but she was still wakened most nights with paroxysms of cough. She was admitted to -hospital to spend time in a mist tent. Kylie's course progressed; by the age of 4 years she was not well enough to leave hospital. She was given oxygen by mask and passed away soon after. It was arranged for her two siblings to have sweat tests. Her 4 yearold brother also had a positive test and died 3 years later. A younger brother had a normal sweat test (sweat chloride $<40 \mathrm{mmol} / \mathrm{L}$ ).

\section{Transformation of cystic fibrosis care 1965-1995 (the Clinical Era)}

There was a significant shift in care and treatments available for a child born with cystic fibrosis in 1995; a child born then had much more to look forward to than in 1965. The clinical situation had improved dramatically with a median survival of 29 years, and CF had become a disease relevant to adult physicians for the first time. This improved survival occurred through advances in nutrition (development of pancreatic enzyme replacement) and refinements in conventional therapies for the chest such as newer antibiotics and more effective methods of airway clearance. In particular there was a wider acceptance of aggressive management of CF in childhood with admissions to hospital for "tune-ups" with intravenous antibiotics and physiotherapist-led airway clearance. These factors substantially slowed the progression of CF. Specialised CF multidisciplinary teams became standard of care.

In much of the world, CF was still a clinical diagnosis. However, in Australia newborn screening for CF was introduced in 1981 (NSW) and allowed infants to be treated before the onset of respiratory symptoms, offering the promise of prevention with early therapy before lung damage occurred. ${ }^{2,3}$ Multi-centre randomised controlled trials (RCTs) of CF therapies were initiated. ${ }^{3}$ The first CF-specific drug, 
developed in 1991 recombinant human DNase (Pulmozyme), was a mucolytic agent whose efficacy was proven by RCT. ${ }^{4}$

\section{Cystic fibrosis in a child born in 1995}

-Caitlin was born in 1995, a healthy baby, with parents who had never heard of CF (94\% of patients with CF have no family history). ${ }^{5}$ At 4 weeks of age her family were informed that the newborn screening blood spot had an elevated enzyme level (immunoreactive trypsinogen, IRT) and a gene test showed she was homozygous for the common CF mutation, "F508. Her sweat chloride was $100 \mathrm{mmol} / \mathrm{L}$, confirming the diagnosis of CF. Her parents were surprised and disappointed that their apparently well baby had this life-shortening disease. She was referred to the multi-disciplinary team at the local CF centre. A faecal fat test was positive for undigested fat (fat globules) and she was commenced on pancreatic enzyme, fat-soluble vitamin and salt replacement. A cough swab showed she was colonised with Staphylococcus aureus and regular antibiotics were commenced. Her parents received education from the physiotherapists and she commenced a daily airway clearance program commenced a daily airway clearance program. Although devastated by the diagnosis, her family were told of the overall significantly better outcome with improvements in standard care. She was seen in the multi-disciplinary clinic monthly in the first 6 months and thereafter 2- to 3- monthly. At every visit, sputum was cultured routinely and her weight gain and annual review progress were assessed. At the age of 5, her sputum cultured Pseudomonas aeruginosa for the first time. She was treated with a new oral anti-pseudomonal antibiotic ciprofloxacin and nebulised tobramycin (iv solution) in an attempt to eradicate the infection. At 6 years of age she started the new CF mucolytic agent, inhaled DNase (Pulmozyme), for her productive cough. By 10 years she was able to perform her own physiotherapy with a positive expiratory pressure (PEP) mask. Although she had some reduction in her lung function ( $\mathrm{FEV}_{1}$ $85 \%$ ) she had excellent growth. A sibling was born after her parents had been offered first trimester amniocentesis which had shown the foetus to be heterozygous of the 
"F508 mutation. Caitlin required a number of admissions to hospital in her teens, but moved to adult CF services after she completed high school. She is currently 20 years old, attending University. Her $\mathrm{FEV}_{1}$ of $75 \%$ reflects an annual rate of decline of $1 \%$ which is the expected rate of decline in this era.

\section{Transformation of cystic fibrosis care 1995-2015 (the Genetic Era)}

The isolation of the 'CF gene' in 1989 gave rise to an explosion of knowledge in the structure and function of cystic fibrosis trans-membrane conductance regulator (CFTR), the protein product of the CFTR gene. ${ }^{6-9}$ Mutations in CFTR have been divided into 6 classes depending on the effect of the mutation on protein (CFTR) production. Classes I-III are associated with no effective CFTR function, while classes IV-VI have residual function, thus explaining the variable phenotype that had puzzled clinicians. ${ }^{10}$ CFTR is an epithelial ion transport protein, predominantly transporting chloride and regulating sodium transport. CFTR is principally located in the epithelium of the airways, pancreatic ducts, bile ducts, gut, vas deferens and sweat ducts. In the lung, abnormal CFTR results in an altered airway surface fluid and dehydrated, viscous mucus that promotes bacterial infection. ${ }^{10}$ The subsequent inflammatory response starts early and results in damage to the airways. ${ }^{11}$

Continued refinements of existing treatments resulted in incremental gains in health and survival. In the mid 2000s a new approach to drug discovery, called high through-put screening, identified a number of compounds that appeared to activate CFTR. One of these was particularly effective for the class III gating mutation, gly551asp (G551D) in which the CFTR protein is correctly positioned in the apical cell membrane, but does not transport chloride. ${ }^{12}$ About $5 \%$ of patients with $\mathrm{CF}$ in Australia have the G551D mutation. Ivacaftor has been shown to realign the intracellular part of the protein and permit improved chloride transport across the cell membrane. In a phase III randomised trial, ivacaftor improved $\mathrm{FEV}_{1}$ by $10 \%$, caused $3 \mathrm{~kg}$ of weight gain and sweat chloride dropped from a mean of $103 \mathrm{mmol} / \mathrm{L}$ to 
$53 \mathrm{mmol} / \mathrm{L}$, below the CF diagnostic level $60 \mathrm{mmol} / \mathrm{L} .{ }^{13}$ By 2015 , ivacaftor was in clinical use in Australia, funded by special arrangement with PBS, at a current cost of A $\$ 300,000$ per child per annum. Drugs (lumicaftor and other investigational drugs) to activate the pF508del mutation are less beneficial in patients homozygous for pF508del, with just 3\% improvement in $\mathrm{FEV}_{1}$ and no nutritional or sweat chloride - effects. ${ }^{14}$ The early results of gene therapy delivered by nebuliser to the airway were disappointing, but the search for a genuine cure continues. ${ }^{15}$

\section{Cystic fibrosis in a child born in 2015}

Kylie (born 1965) had a younger brother David, who had routine sweat testing as a sibling of a patient with $\mathrm{CF}$. He did not have $\mathrm{CF}$, but carrier testing was not offered until he was an adult. ${ }^{16}$ When he decided to start a family, David and his partner were offered pre-pregnancy screening for CF that would determine if they carried any of the 38 most common CFTR gene mutations. ${ }^{17}$ They decided against screening and subsequently delivered a $3.6 \mathrm{~kg}$ boy at term in 2015 . Four weeks after birth they were contacted by the genetic counsellor attached to the newborn screening service informing them that their son, Peter, had CF. Peter had an elevated neonatal immunoreactive trypsinogen (IRT) and was then found to have two known disease causing CF mutations phe508del and gly551asp. A sweat chloride test confirmed the diagnosis. The family were seen later that week by the multi-disciplinary CF care team for education about $\mathrm{CF}$ and initial investigations on Peter including faecal elastase (the gold standard for detection of pancreatic insufficiency), chest X-ray and blood tests including liver function testing and fat soluble vitamins. Peter commenced on antibiotic prophylaxis (amoxicillin-clavulanate), pancreatic enzyme replacement (Creon microspheres), fat-soluble vitamins (vitaBDEK) and salt replacement. He commenced twice daily airway clearance ("chest physiotherapy"), initially chest percussion with a plan to progress to blowing bubbles, trampoline work and later a variety of positive end-expiratory pressure devices (PEP) that would eventually help him to be independent in his cares. The family received education in daily CF care 
including enzyme administration, high fat and protein diet and chest physiotherapy. They met all members of the hospital based multi-disciplinary CF care team as well as the community based CF nurse and physiotherapist. Peter was seen by the whole multi-disciplinary team in CF outpatients every month for the first year of his life and then every second month, in a room separate from all other CF patients (to reduce -cross infection). ${ }^{18}$

At his annual review clinic visit later that year the findings of his surveillance chest computerised tomographic (CT) scan were discussed and the noted peri-bronchial wall thickening prompted the institution of daily mucolytic therapy using Pulmozyme.[11] When he was 4 years old, Peter was found to have Pseudomonas aeruginosa on a bronchial lavage performed because of failure of a productive cough to clear on prolonged oral antibiotics. He was admitted to hospital for a 14-day eradication program of dual antibiotics and physiotherapy. Nebulised hypertonic saline 6\% (developed in Australia as a mucolytic agent) was added to his airway clearance regimen while he remained productive of sputum. He was discharged home on day 5 of the admission to continue the remainder of his treatment at home under the Hospital-in-the-Home programme. Following admission he continued Pseudomonas eradication therapy for 2 months with nebulised TOBI $\mathbb{B}$ (purified tobramycin for inhalation, the second CF-specific medication developed). His slow weight gain concerned the $\mathrm{CF}$ gastroenterologist and $\mathrm{CF}$ dietician. The $\mathrm{CF}$ psychologist worked with the family to address adherence with treatment recommendations. An oral nutritional supplement (Sustagen) was started with improvement in weight gain.

When Peter turned 6, he became eligible for the CFTR mutational-specific drug ivacaftor (Kalydeyco). Within 3 months he had 12\% improvement in $\mathrm{FEV}_{1}$, gained 2 $\mathrm{kg}$ of weight and his sweat chloride dropped to $52 \mathrm{mmol} / \mathrm{L}$. Peter was able to cease regular antibiotic therapy and nutritional supplements, but remained on pancreatic enzyme replacement. 
At the age of 10, an oral glucose tolerance study performed as part of his annual review showed impaired glucose tolerance but not sufficient to meet the diagnostic criteria for cystic fibrosis-related diabetes (post glucose dose BSL at 2 hour of > $11.1 \mathrm{mmol}$ ). He was enrolled in a trial of early administration of insulin being - conducted by the CF endocrinologist associated with the CF care team. At 16, he commenced 6-monthly outpatient clinic visits with the hospital's transition team in preparation for his transfer to the Adult CF unit at the end of his secondary education.

\section{Epilogue: the future: cystic fibrosis (2065)}

The first in utero trial of CF corrective stem-cell therapy has just been completed. Sally aged 29 years was part of the trial. Sally's partner was found to be a CF carrier at the age of 16 when he undertook whole genome sequencing, introduced in his high school biology program. Sally was known to be a carrier because she was conceived by IVF pregnancy, her father Peter (born 2015) having CF with bilateral absence of the yas deferens. Peter has been on CFTR rescue molecular therapy since 6 years of age, one of over 1000 patients in the adult CF clinic, seen twice per year for surveillance. Maternal free DNA testing reveals the fetus is affected with two CFTR gene mutations. Peter holds his breath, and he has plenty of it ( $\mathrm{FEV}_{1} 88 \%$ predicted), waiting for the result of Sally's first surveillance ultrasound. On Sally's 20-week fetal ultrasound there is no evidence of echogenic bowel, the pancreatic ducts are normal and vas deferens patent. Bennie is born at 38 weeks gestation and the newborn screening blood spot shows two CFTR mutations. Nasal brushing reveals respiratory epithelium fully transfected by replacement CFTR. Rectal biopsy derived artificial organoid creation reveals normal electrolyte transport. Bennie leaves hospital at 24 hours of age (delayed by having testing). He'll be seen by a molecular physician in the new 65 bed Children's Hospital (30 ICU beds, 35 acute inpatient beds, 215 hospital-in-the-home "beds") built on the site of a disused park, where records show there used to be an old children's hospital. 


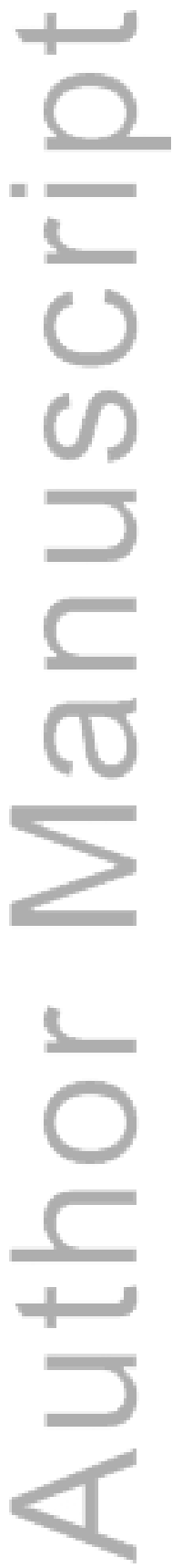

This article is protected by copyright. All rights reserved. 


\section{References}

1. Isaacs D. The Journal of Paediatrics and Child Health is celebrating its 50th anniversary. J. Paediatr. Child Health. 2015;51:1-2.

2. Wilcken B, Brown AR, Urwin R, et al. Cystic fibrosis screening by dried blood spot trypsin assay: results in 75,000 newborn infants. J. Pediatrics 1983;102:383-7.

2. Wilcken B, Chalmers G. Reduced morbidity in patients with cystic fibrosis detected by neonatal screening. Lancet 1985;2:1319-21.

3. Gibson RL, Burns JL, Ramsey BW. Pathophysiology and management of pulmonary infections in cystic fibrosis. Am. J. Respir. Crit. Care Med 2003;168:918-51.

4. Fuchs HJ, Borowitz DS, Christiansen DH, et al. Effect of aerosolized recombinant human DNase on exacerbations of respiratory symptoms and on pulmonary function in patients with cystic fibrosis. The Pulmozyme Study Group. N. Engl. J. Med. 1994;331:637-42.

5. McClaren BJ, Metcalfe SA, Aitken M, et al. Uptake of carrier testing in families after cystic fibrosis diagnosis through newborn screening. Eur. J. Human Genetics.

2010;18:1084-9.

6. Kerem B, Rommens JM, Buchanan JA, et al. Identification of the cystic fibrosis gene: genetic analysis. Science 1989;245:1073-80.

7. Rommens JM, Iannuzzi MC, Kerem B, et al. Identification of the cystic fibrosis gene: chromosome walking and jumping. Science. 1989;245:1059-65.

8. Riordan JR, Rommens JM, Kerem B, et al. Identification of the cystic fibrosis gene: cloning and characterization of complementary DNA. Science. 1989;245:1066-73.

9. Welsh MJ, Smith AE. Molecular mechanisms of CFTR chloride channel dysfunction in cystic fibrosis. Cell 1993;73:1251-4.

10. Rowe SM, Miller S, Sorscher EJ. Cystic fibrosis. N. Engl. J. Med. 2005;352:19922001

11. Pillarisetti N, Linnane B, Ranganathan S. Early bronchiectasis in cystic fibrosis detected by surveillance CT. Respirology. 2010;15:1009-11.

12. Accurso FJ, Rowe SM, Clancy JP, et al. Effect of VX-770 in persons with cystic fibrosis and the G551D-CFTR mutation. N. Engl. J. Med. 2010;363:1991-2003.

13. Ramsey BW, Davies J, McElvaney NG, et al. A CFTR potentiator in patients with cystic fibrosis and the G551D mutation. N. Engl. J. Med. 2011;365:1663-72.

14. Wainwright CE, Elborn JS, Ramsey BW, et al. Lumacaftor-Ivacaftor in Patients with Cystic Fibrosis Homozygous for Phe508del CFTR. N. Engl. J. Med. 2015;373:220-31.

15. Alton EW, Armstrong DK, Ashby D, et al. Repeated nebulisation of non-viral CFTR gene therapy in patients with cystic fibrosis: a randomised, double-blind, placebocontrolled, phase 2b trial. Lancet Resp. Med. 2015;3:684-91.

16. Vears DF, Delany C, Massie J, et al. Parents' experiences with requesting carrier testing for their unaffected children. Genet. Med. Published online 24 March 2016. doi: 10.1038/gim.2016.24.

17. Sawyer SM, Cerritelli B, Carter LS, et al. Changing their minds with time: a comparison of hypothetical and actual reproductive behaviors in parents of children with cystic fibrosis. Pediatrics. 2006;118:e649-e656. 
18. Griffiths AL, Wurzel DF, Robinson PJ, et al. Australian epidemic strain pseudomonas (AES-1) declines further in a cohort segregated cystic fibrosis clinic. J. Cystic Fibrosis. 2012;11:49-52.

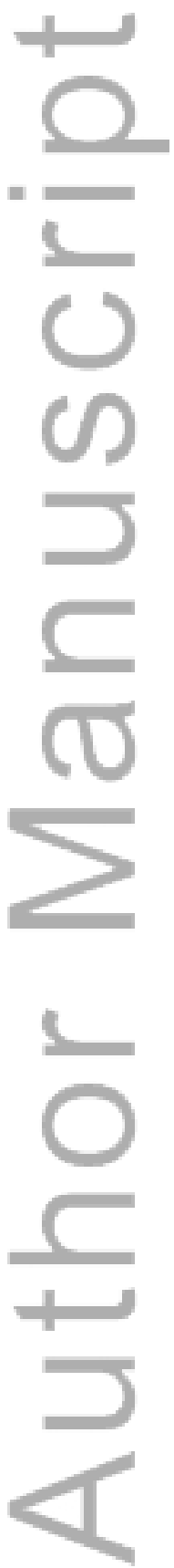

This article is protected by copyright. All rights reserved. 


\section{University Library}

\section{- M M I E E R VA A gateway to Melbourne's research publications}

Minerva Access is the Institutional Repository of The University of Melbourne

Author/s:

Massie, J;Robinson, PJ;Cooper, PJ

Title:

The story of cystic fibrosis $1965-2015$

Date:

2016-11-01

Citation:

Massie, J., Robinson, P. J. \& Cooper, P. J. (2016). The story of cystic fibrosis 1965-2015. JOURNAL OF PAEDIATRICS AND CHILD HEALTH, 52 (11), pp.991-994. https:// doi.org/10.1111/jpc.13309.

Persistent Link:

http://hdl.handle.net/11343/291669 